\title{
AUDIOTACTILE MAPS AS A FACILITATING ELEMENT IN SPATIAL ORIENTATION AND MOBILITY
}

\author{
Veronika Ruzickova \\ Institute of Special Education Studies, Palacky University, Czech Republic \\ Katerina Kroupova \\ Institute of Special Education Studies, Palacky University, Czech Republic
}

\begin{abstract}
Tactile graphics represent an important means to overcome or alleviate the information deficit resulting from the loss of visual perception. The research framework of the paper is focused on a primary probe into the field of application of tactile graphics in the spatial orientation of people with visual impairment in the sense of development of spatial imagination and improvement of independent movement through the use of audiotactile maps. The chosen topic is viewed from the perspective of professionals working with people with visual impairment as well as the clients with visual impairment themselves. Partial results of the study are presented, focusing on the overall attitude of people with visual impairment to tactile graphics and their application potential, which adds to the overall picture of contemporary reality in the field of tactile graphics, with an emphasis on usability in spatial orientation and independent movement. The research has shown the considerable potential of tactile graphics in the development of spatial imagination. In connection with these conclusions, modern $3 \mathrm{D}$ maps with auditory elements were designed and will be also presented in the paper.
\end{abstract}

Keywords: audiotactile maps, people with visual impairment, spatial orientation and mobility.

\section{Introduction}

The aim of the submitted contribution is to introduce a research framework in the area of tactile graphics with emphasis on the field of spatial orientation and individual mobility.

Tactile graphics intended for persons with visual impairment can represent a significant means of overcoming or reducing the information deficit originating due to restriction or loss of visual perception.

Despite the current preference for information received auditorily, tactile graphics still remain a significant information carrier. What is key is the function of tactile graphics in terms of improvement and support of the dynamic development of perception. In response to improved perception, the imagination develops - spatial ideas are refined, deepened and extended, as is thinking in terms of integration of the individual elements into a whole with respect to exploration 
of the surrounding world (Finková, Ludíková, \& Růžičková, 2007; Růžičková, Kroupová, \& Vondráková, 2018). Practically, tactile graphics is primarily of benefit within the area of spatial orientation and independent mobility, in particular, in terms of tactile plans and maps.

Searching for other ways to improve the spatial knowledge of and ignite the spatial imagination of persons with visual impairment is an important challenge faced by contemporary society. A number of studies focused on the application of tactile graphics, especially in the area of spatial orientation and tactile maps - for example Caddeo, Fornara, Nenci, \& Piroddi, 2006; Espinoza \& Ochaita, 1998; Espinoza, Ungar, Ochaita, Blades, \& Spencer, 1998; Jacobson, 1992, 1998; Jacobson \& Kitchin, 1995; Passini \& Proulx, 1988; Thorndyke \& Hayes-Roth, 1982; Ungar, 2000 (Kroupová, 2019).

The ability to move efficiently depends on the ability to construct and use a mental representation of the surroundings (Picard \& Pry, 2009). The process whereby the spatial pieces of information are integrated into a mental representation is called cognitive mapping (Downs, Stea in Picard, \& Pry, 2009). The aforementioned mental representations can be based both on direct, explicit knowledge of the route (mastered based on practice with instructor), and on mediated knowledge of the route through tactile maps or plans (Thinus-Blanc, Gaunet in Picard, \& Pry, 2009).

The ability to construct efficient spatial representations develops gradually during life (Siegel, White in Picard, \& Pry, 2009). Various authors point out the fact that deficiencies in the spatial skills of persons with visual impairment do not reflect a low level of education but rather an alternative means of embracing space in terms of coding and behavioural strategy (Thinus-Blanc a Gaunet in Picard \& Pry, 2009). It is tactile maps that prove to be the relevant tools for increasing the knowledge of spatial configuration in the population of persons with visual impairment (Espinoza et al.; Ungar et col. in Picard \& Pry, 2009). The results of these studies have shown that tactile maps help in creating spatial relationships better than direct experience in a real environment (Caddeo et al., 2006; Jacobson, 1998 in Picard, Pry, 2009) (Kroupová, 2019).

One such option of making tactile map is the use of 3D printing. 3D printers are currently a relatively inexpensive solution for rendering reality in tactile form. As part of our contribution, we would like to focus on introducing a project that presents space for people with visual impairments using audio-tactile maps. The production of tactile maps has a long history thanks to the Department of Geoinformatics and its cooperation with the Institute of Special Education Studies. Although expensive 3D gypsum maps were produced from in 2010, we have now begun production on a new generation of maps.

This new generation of maps is based on the possibility of printing parts of the map with conductive material, which behaves as a conductor when 
encountering a touch screen (mobile phone, tablet or monitor) and thus triggers a special sounding part of the screen (see figure 1a). These will be presented in the last part of the paper.

\section{Methodological framework}

The scope of this research is focussed on a primary probe of the applicability of tactile graphics in spatial orientation and independent mobility among professionals and persons with visual impairment. The key premises of our study focus on the overall approach of persons with visual impairment to the use of tactile representation, the practical applicability of these representations within Orientation \& Mobility, and the opinions of the professional public on the graphic representation as well as on the nature of this type of representation.

Based on the study of specialised literature and resources, several key questions arose:

1. What is the information benefit of tactile graphics for persons with visual impairment?

2. What is the applicability of tactile graphics within the area of spatial orientation and independent mobility from the perspective of visually impaired persons?

3. What is the information benefit of tactile graphics in the context of spatial orientation from the perspective of professionals working with people with visual impairment?

4. What should the characteristics of tactile graphics be, from the perspective of persons with visual impairment and interested professionals?

5. Does major society have adequate tactile elements in public space?

6. Are tactile graphics commonly used in activities of daily living of people with visual impairment?

7. Do tactile graphics also fulfil an aesthetic function for persons with visual impairment?

We proposed a quantitative research design that was represented by a questionnaire method. The primary research set was saturated based on intentional selection and the respondents were selected based on their visual impairment regardless of the degree. The secondary research set was made up of professionals working with persons with visual impairment.

The primary research set consists of 15 respondents of different ages (mostly young adults) with various visual impairments. Two thirds of the primary research file respondents are persons with congenital severe visual impairment or an impairment which originated at an early age (blindness, residual sight, severe vision impairment), which can be considered as a significant indicator of the 
research validity. The secondary research set contains 16 professionals with various practice length, with $60 \%$ of professionals in practice longer than 15 years. These data imply adequate competences for assessment of the area of interest and highly relevant opinions of professionals. Moreover, $60 \%$ of the respondents completed a course, training or workshop focusing on tactile graphics for persons with visual impairment.

Respondents from the research sets were administered a questionnaire consisting of open items with space for free association and closed items with scaling. The data collection was implemented through on-line communication (organisations in the territory of the whole Czech Republic were addressed). At the same time, the snowball sampling method was applied, for ensuring sufficient saturation of the research sets.

Within the data analysis, illustrative methods of representation in the form of tables were used. Considering the insufficient saturation of the research sets, it was not possible to test the data statistically; therefore, the interpretation has an a priori descriptive and qualitative nature. A few questions were aimed at providing a free associative space for the most authentic answers - therefore, we will not cross the borders of pure description in the analysis and interpretation and will utilise the methods intended for qualitative research primarily (bunching, contrasting, etc.). Due to the above, it is not possible to generalise the acquired data; therefore, the results will be interpreted predominantly in relation to theory (Kroupová, 2019).

\section{Findings}

The result of our study is a unique complex image of the current reality regarding tactile graphics intended for persons with visual impairment. Emphasis is placed on the information benefit of those graphics in the field of spatial orientation and independent mobility, from the perspective of persons with visual impairment and professionals working with persons with visual impairment. Part of this research, mostly qualitative data, was introduced at 10th ICEEPSY 2019, the 10th International Conference on Education \& Educational Psychology and was published in The European Proceedings of Social and Behovioural Sciences, EPSBS. Qualitative data analysis revealed the dominance of cartographic information in tactile representation, in particular in relation to the mobility and orientation in persons with visual impairment.

The following section contains evaluation in terms of pure description of results using tables with percentage values. Considering the low saturation of the research sets, it is not possible to test the data statistically. The results only provide an input illustrative scope of the topic in question. 
SOCIETY. INTEGRATION. EDUCATION

Proceedings of the International Scientific Conference. Volume IV, May $22^{\text {th }}-23^{\text {th }}, 2020.120-129$

Table 1 Tactile information as the support element in O\&M

\begin{tabular}{|c|c|c|}
\hline $\begin{array}{l}\text { Tactile information as the } \\
\text { support element in O\&M }\end{array}$ & $\begin{array}{l}\text { Primary research set } \\
\text { (relative frequency) }\end{array}$ & $\begin{array}{l}\text { Secondary research set } \\
\text { (relative frequency) }\end{array}$ \\
\hline Yes & $26.7 \%$ & $87.5 \%$ \\
\hline No & $73.3 \%$ & $12.5 \%$ \\
\hline Specific elements & $\begin{array}{l}\text { Guide lines } \\
\text { Tactile pavement } \\
\text { Maps } \\
\text { Intersection plans } \\
\text { Working with details }\end{array}$ & $\begin{array}{l}\text { Guide lines } \\
\text { Tactile pavement } \\
\text { Maps } \\
\text { Route plans } \\
\text { Plans of important buildings, } \\
\text { municipality, stations }\end{array}$ \\
\hline
\end{tabular}

The discrepancy in the attitude of persons with visual impairment and the professional public can be considered rather disturbing; however, the enumeration of particular tactile elements in the spatial orientation corresponds in both research sets. The said discrepancy could be caused by inadequate understanding of the term "typhlography" in relation to spatial orientation.

Table 2 Experience with tactile maps

\begin{tabular}{|l|l|l|}
\hline $\begin{array}{l}\text { Experience with tactile } \\
\text { maps }\end{array}$ & $\begin{array}{l}\text { Primary research } \\
\text { set (relative } \\
\text { frequency) }\end{array}$ & $\begin{array}{l}\text { Secondary research set (relative } \\
\text { frequency) }\end{array}$ \\
\hline Yes & $66.7 \%$ & $93.8 \%$ \\
\hline No & $33.3 \%$ & $6.3 \%$ \\
\hline Benefit & $33.3 \%$ & $62.5 \%$ \\
\hline Place of exposure & School & $\begin{array}{l}\text { Institutions and organisations for persons } \\
\text { with visual impairment } \\
\text { Studies } \\
\text { Within O\&M teaching } \\
\text { Own production } \\
\text { In educating pupils with visual impairment } \\
\text { Embossments in town centres } \\
\text { Exhibition }\end{array}$ \\
\hline Comment & $\begin{array}{l}\text { "They are more suitable for additional } \\
\text { illustration of the terrain situation rather } \\
\text { than as an exclusive source of } \\
\text { information." }\end{array}$ \\
\hline
\end{tabular}

Both research sets confirmed considerable experience with tactile maps. What we consider as positive is the dominance of school as the mediator of contact with tactile maps. However, it is important to note that there are two school streams that members of our primary population may enter: special education versus inclusive (mainstreamed) schooling, and the tools utilised in special education settings are not often available in mainstream classrooms. For 
illustration, we provide one of the comments of a professional respondent: “(...) in inclusive education (common school), I think they will not come across typhlographics at all. In schools for children with visual impairment, I hope they do (...).” This item also accentuates the role of relief maps in spatial orientation.

Table 3 Demand for 3D models

\begin{tabular}{|l|l|l|}
\hline $\begin{array}{l}\text { Demand for 3D models by } \\
\text { persons with visual } \\
\text { impairment }\end{array}$ & $\begin{array}{l}\text { Primary research } \\
\text { set (relative } \\
\text { frequency) }\end{array}$ & $\begin{array}{l}\text { Secondary research set (relative } \\
\text { frequency) }\end{array}$ \\
\hline Yes & $80.0 \%$ & $93.8 \%$ \\
\hline No & 0.0 & 0.0 \\
\hline I don't know & $20.0 \%$ & $6.3 \%$ \\
\hline Comment & $\begin{array}{l}\text { It would surely be suitable (to increase the } \\
\text { number of 3D models of monuments) - in } \\
\text { rinciple, but I believe that it would not } \\
\text { increase the number of visually impaired } \\
\text { visitors and their interest - this option } \\
\text { would be still used by the same persons. }\end{array}$ \\
\hline
\end{tabular}

The results confirm a greater demand for tactile information in the public space than has been met at this time, which was also evident within the highquality data analysis.

Table 4 Awareness of current trends in typhlocartography

\begin{tabular}{|l|l|l|}
\hline $\begin{array}{l}\text { Awareness of the new possibilities of } \\
\text { connection to haptic and auditory } \\
\text { information }\end{array}$ & $\begin{array}{l}\text { Primary research set } \\
\text { (relative frequency) }\end{array}$ & $\begin{array}{l}\text { Secondary research set } \\
\text { (relative frequency) }\end{array}$ \\
\hline Yes & $73.3 \%$ & $81.3 \%$ \\
\hline No & $26.7 \%$ & $18.8 \%$ \\
\hline
\end{tabular}

Respondents from both research sets confirm a sufficient level of awareness regarding modern trends in the field of typhlocartography. However, the absence of typhlocartographic elements in public space remains an issue.

In correspondence with our assumption, tactile graphics dominated in the area of spatial orientation, with the role of tactile maps, plans and 3D models being emphasised across a majority of the items examined (Kroupová, 2019).

We also dealt with other aspects of research (eg information contribution of tactile graphics, possibilities to overcome the information deficit, development of spatial imagination, contribution to spatial orientation). Interestingly, in most cases both research sets were in conflict with each other. However, respondents from both research sets agreed on the benefits of tactile graphics for area of spatial orientation and independent mobility. These aspects were presented at 10th 
ICEEPSY 2019, the 10th International Conference on Education \& Educational Psychology and was published in The European Proceedings of Social and Behovioural Sciences, EPSBS. Further research results are available in the aforementioned conference proceedings.

\section{Practical applications}

The results of the survey presented above showed us another possible way to improve the training of spatial orientation, in addition to strengthening the image of the surroundings, or repeating some of the routes already used. This option is working with maps and plans. Maps as the most ubiquitous products of geovisualisation are a natural part of humankind because most of the information around us is linked to the geospatial location. More than $85 \%$ of our perceptions are received by eyesight; therefore the majority of maps are produced for reading with eyes. In general, people with visual impairment perceive the world differently, so the creation of a tactile map for these users is conceptually different, more expensive and more difficult compared to normal maps.

The content of maps and their form must be relevant to the level of education In general, user issues in cartography focus on map use, cognitive aspects, user needs, and user preferences. User issues are essential in cartographic education and cartographic research, and their importance is growing with the specificity of requirements for the training of people with visual impairments. (Vondráková \& Rủžičková, 2018; Vondrakova, 2016)

Since 2018, the project TACR (Technical Agency of the Czech Republic) Perception of geospatial via 3D audio-tactile maps has been in progress at Palacký University in Olomouc. This project is currently in the final third and we can share some of the conclusions that have come from testing both classical tactile plans and maps, as well as their audio-tactile versions.

"The output of the project will be the prototype of the tactile-auditory maps, which are created by the 3D printing method with a link to the TactileMapTalk software (figures 1a, 1b). The software, together with the printed series of maps, will be the central tool for audio tactile learning. TactileMapTalk will teach users how to work with the map, following the sub-tasks in the educating materials. As a result, the user will be able to effectively use the map with the iPad while practicing a separate movement. The software will be created under an open Creative Commons license. The map set is composed from sub-maps which represent the parts (data layers) that a visually impaired individual learns to recognize. A comprehensive map containing all layers is then better to understand and the user gains the skills to work with similar tools automatically. The upcoming 3D map type has not been created yet in any research. Good training 
will be required to understand and manage the orientation in the map." (Hrbacova \& Ruzickova, 2018)

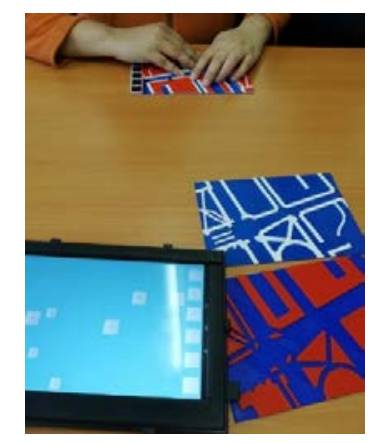

Figure 1a Set of maps with tablet

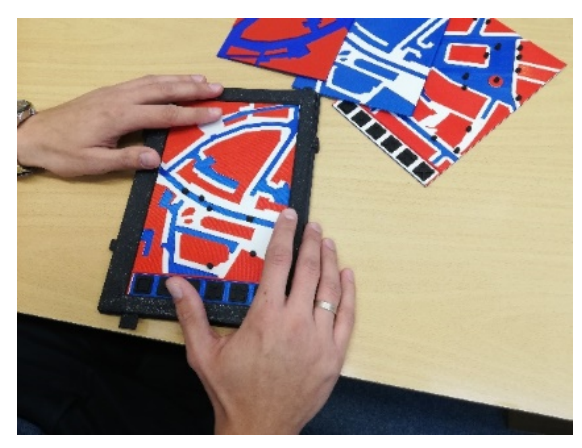

Figure $1 b$ Tablet with a map

The maps have been tested by a wide range of users - both in terms of age and the degree of visual impairment. The maps were tested both in schools for pupils with visual impairments and in organizations for people with visual impairments.

The main outcomes of testing were the following:

- For people with severe visual impairment, the contrast should be considered - maps were printed in blue, yellow and red, but after the first testing, the yellow colour was replaced with white.

- $\quad$ By blind people - perhaps the most interesting outcome was a finding we had been aware of from the beginning of the project. With 3D printers, maps can be printed with greater accuracy and fewer distances between two edges or two points, in comparison to traditionally produced maps.

"Tactile graphics is understood as a special scientific discipline dealing with graphic presentation for the blind persons. The fundamental elements of tactile graphics are relief point, relief lines and relief pattern (texture). It is not allowed to exceed the minimum dimensions in the graphic realization of tactile maps. The tactile graphic elements, their mutual distances and other fundamental parameters are defined as follows by Jesenský: relief point - minimum diameter at the base of $1.2 \mathrm{~mm}$, minimum height of the relief point $0.75 \mathrm{~mm}$, minimum spacing of $1.2 \mathrm{~mm}$ at the base and minimum spacing in the top $2.4 \mathrm{~mm}$; relief line - preferably a parabolic shape with a height to width ratio of $3: 2$; relief pattern - the width of the baseline depends on the used technology, the smallest width of two relief pattern and two embossed edges, 3 to $5 \mathrm{~mm}$. Additionally, it is important to adapt the suitable size of the map according to user needs. This is the main reason why it is 
really important to implement user studies into the research dealing with tactile cartography and tactile map production.” (Vondráková, Růžičková, \& Barvíř, 2018)

- $\quad$ For both groups of respondents were linking tactile maps with voice guidance, instructions, and tasks, which is equipped with our software for tablets motivating and interesting.

\section{Conclusions}

Spatial orientation is an integral part of our lives and at the same time it is one of the areas that is the most significant sending to people with severe visual impairment as a result of loss of visual perception.

Spatial orientation and independent movement have long been seen in terms of the need for long-term training and remembering the route. From the beginning everything was based on the individual's abilities and verbal description associated with the experience. Then we began to think about how to translate space into a tangible form, and we gradually moved from plans and maps engraved in clay or sand, to those made of various felt and materials glued to each other. However, this is not enough in modern times and is also unnecessary becase we now have a large number of available 3D imaging methods. In our paper, we focused on two basic things - perception of space, typhlography and the connection of these two areas from the perspective of people with visual impairments and experts, and then a brief delimitation of the project dealing with audiotactile maps.

Our intention in the investigation was to probe a selected area of interest and to identify interesting aspects that could be explored within an applied research program. Obviously, tactile graphics have an ideal information potential especially in the area of spatial orientation and limited mobility. The aspects identified above can be a useful guide for designing applied research.

\section{Acknowledgements}

This paper was created within the project Development of independent movement through tactile-auditory aids, No. TL01000507, supported by the Technology Agency of the Czech Republic.

\section{References}

Finková, D., Růžičková, V., \& Ludíková, L. (2007). Speciální pedagogika osob se zrakovým postižením. Olomouc: Univerzita Palackého v Olomouci.

Hrbáčová, L., \& Růžičková, V. (2018). Development of independent movement through tactile - auditory means. In 5th International multidisciplinary scientific conference on 
social sciences and arts SGEM 2018. Conference proceedings Volume 5 (p. 181 - 188). Bulgaria: Stef92 Technology.

Kroupová, K. (2019). The Perception as a facilitating Information Element in the Spatial Orientation. In The European Proceedings of Social and Behovioural Sciences. EPSBS. Volume LXXII (p. 582 - 591).

Picard, D., \& Pry, R. (2009). Does knowledge of spatial configuration in adults with visual impairments improve with tactile exposure to a small-scale model of their urban environment? Journal of Visual Impairment \& Blindness, 103(4), 199-209.

Růžičková, V., Kroupová, K., \& Vondráková, A. (2018). Counselling for People with Visual Impairment in the Czech Republic. In 4th International Conference on Lifelong Education and Leadership for all, ICLEL 2018, Conference proceeding Book (p. 254 - 260). Sakarya: Sakarya University Faculty of Education.

Vondráková, A., \& Růžičková, V. (2018). The Importance of User Issues in the Cartographic Education of People with Visual Impairment. In 4th International Conference on Lifelong Education and Leadership for all, ICLEL 2018, Conference proceeding Book (p. 250 - 253). Sakarya: Sakarya University Faculty of Education.

Vondráková, A., Ruzickova, V., \& Barvir, R. (2018). User issues in tactile cartographic education. in 5th International multidisciplinary scientific conference on social sciences and arts SGEM 2018. Conference proceedings Volume 5 (p. 913 - 920). Bulgaria: Stef92 Technology.

Vondráková, A. (2016). User Issues in Geovisualization. In 6th International Multidisciplinary Scientific GeoConference SGEM 2016. Proceedings Book2 Vol. 3 (p. 599-606). Sofia: STEF92 Technology. 